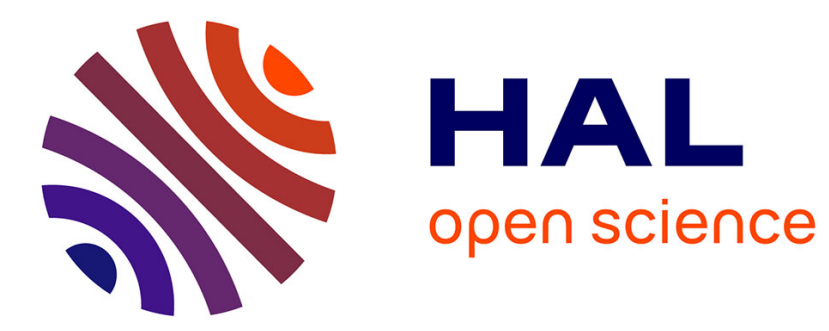

\title{
Modelling analysis of centroid curves of olfactory habituation in humans
}

\author{
Eric Laffon, Thomas Hummel, Roger Marthan, Charlotte Sinding
}

\section{To cite this version:}

Eric Laffon, Thomas Hummel, Roger Marthan, Charlotte Sinding. Modelling analysis of centroid curves of olfactory habituation in humans. Physiology \& behavior, 2020, 214, pp.112751. 10.1016/j.physbeh.2019.112751 . hal-02627430

\section{HAL Id: hal-02627430 \\ https://hal.inrae.fr/hal-02627430}

Submitted on 21 Dec 2021

HAL is a multi-disciplinary open access archive for the deposit and dissemination of scientific research documents, whether they are published or not. The documents may come from teaching and research institutions in France or abroad, or from public or private research centers.
L'archive ouverte pluridisciplinaire HAL, est destinée au dépôt et à la diffusion de documents scientifiques de niveau recherche, publiés ou non, émanant des établissements d'enseignement et de recherche français ou étrangers, des laboratoires publics ou privés.

\section{(ㄷ)(1) $\$$}

Distributed under a Creative Commons Attribution - NonCommercial| 4.0 International 


\section{Modelling analysis of centroid curves of olfactory habituation in humans}

\section{Eric Laffon ${ }^{1,2,3}{ }^{*}$, Thomas Hummel ${ }^{4}$, R. Marthan 1, 2,3, Charlotte Sinding 5}

${ }^{1}$ CHU de Bordeaux, Departments of Nuclear Medicine \& Lung Function Testing, Bordeaux, France.

${ }^{2}$ Univ. Bordeaux, Centre de Recherche Cardio-Thoracique, INSERM U-1045, Bordeaux France.

${ }^{3}$ Inserm, Centre de Recherche Cardio-Thoracique, INSERM U-1045, Bordeaux France.

${ }^{4}$ Interdisciplinary Center on Smell \& Taste, Department of Otorhinolaryngology, TU

Dresden, Dresden, Germany.

${ }^{5}$ Centre des Sciences du Goût et de l'Alimentation, CNRS, UMR 6265, INRA, UMR 1324, Université de Bourgogne, Dijon, France.

\section{*Corresponding authors:}

Dr Eric Laffon, Service de Médecine Nucléaire, Hôpital du Haut-Lévêque,

Avenue de Magellan, 33604 PESSAC, France.

Telephone number: +33557656838.

Fax number: +33557656839.

E-mail address: elaffon@u-bordeaux.fr 


\section{Highlights}

- Olfactory habituation $(\mathrm{OH})$ can be considered an unconscious signal filtering

- Three centroid curves reflecting high-middle-low $\mathrm{OH}$ have been previously published

- Adjusting parameters of a general derived equation allowed us to fit each curve

- High correlation coefficients of 0.9997-0.9995-0.9962 were found 


\section{ABSTRACT}

Previously published experiments established the time-course of olfactory habituation in humans, and extracted 3 centroid curves from clustering analysis that reflected high, middle and low habituation. The aim of the current theoretical study was to further analyze these previous experimental data by developing a mathematical modelling analysis designed for fitting the 3 curves from a general equation. After adjusting equation parameters for each curve, fitting equation outcomes on experimental data yielded high correlation coefficients of $0.9997-0.9995-0.9962$, respectively. A model-based interpretation of olfactory-habituation centroid curves is proposed suggesting that they result from the effect of 2 separate processes that act simultaneously. We suggest that the first process is unlikely related to the olfactory habituation itself, and, rather, is of unclear origin. The second process seems to play a major role in the degree of $\mathrm{OH}$ and cannot be assigned, a priori, to either peripheral or central adaptation, respectively.

Keywords: Human olfactory habituation; Modelling analysis; Curve fitting. 


\section{Introduction}

Olfactory habituation $(\mathrm{OH})$ can be considered an unconscious filter whose role is to avoid brain overstimulation [1-5]. New determinants of $\mathrm{OH}$ have been reported in humans by Sinding et al., showing that reduced responsiveness to a continuous or repetitive stimulation depends on some properties of the odorant, notably trigeminality and associated physicochemical characteristics [6]. In these previous experiments, the course of odor intensity of 32 different odorants, which differed in physicochemical characteristics and were presented at constant flow during 120 s, was rated continuously by 58 participants. A k-means clustering analysis of the 1856 recorded curves allowed the authors to partition the data into 3 clusters, thus providing 3 normalized centroid curves representing high, middle and low habituation $(\mathrm{HH}, \mathrm{MH}, \mathrm{LH})$, respectively. The current study focuses on the $\mathrm{HH}-\mathrm{MH}-\mathrm{LH}$ experimental data that were re-analyzed by means of a mathematical modelling analysis in order to provide further model-based information about the processes and mechanisms underlying $\mathrm{OH}$ centroid curves in humans.

In line with Sinding et al. [6], we used, in the current study, the term habituation for the perceptual decrement of odor intensity [4,7], and adaptation when addressing the underlying mechanisms. The term peripheral adaptation encompasses all the adaptation mechanisms that may occur at the receptor level, and the term central adaptation encompasses all the adaptation mechanisms that tune the olfactory signal coming up from the olfactory neurons [7]. Likewise, in this study, 2 adaptation mechanisms were considered, namely, intensity-limiting and intensity-decreasing mechanisms, which were not assigned to either peripheral or central adaptation, respectively. More specifically, the term of intensity-limiting mechanism referred to the situation where the odor intensity (i.e., the signal) under constant odorant-concentration conditions cannot increase with time above a certain value. The term of intensity-decreasing mechanism referred to the situation where the odor intensity (i.e., the 
signal) decreases with time even if the odorant concentration is constant. Noteworthy, this definition only considered a time-dependency of the two mechanisms and investigating the role of a dose-dependency was out of the scope of the current study, as well as of the previous one [6].

Although the comparison of $\mathrm{HH}-\mathrm{MH}-\mathrm{LH}$ centroid curves emphasized the differential filtering of the olfactory signal, depending on the odorant, we nevertheless suggest that the 3 different centroid curves share a common set of processes, each involving intensitylimiting and intensity-decreasing mechanisms, without assigning, a priori, any process or any mechanism to either peripheral or central adaptation. Therefore, the aim of the current study was to derive a general equation of the $\mathrm{OH}$ centroid curves from a mathematical modelling analysis, involving intensity-limiting and intensity-decreasing parameters whose value can be adjusted to fit each experimental $\mathrm{OH}$ centroid curve. 


\section{Material and methods}

\subsection{Mathematical modelling analysis}

We assume that the rate of change in the $\mathrm{OH}$ signal, i.e., $\mathrm{dS}(\mathrm{t}) / \mathrm{dt}$, can be written as:

$$
\mathrm{dS}(\mathrm{t}) / \mathrm{dt}=\mathrm{L}(\mathrm{t}) \times \mathrm{N}_{0}-\mathrm{k}_{\mathrm{dec}} \times \mathrm{S}(\mathrm{t})
$$

where (i) $\mathrm{L}(\mathrm{t})$ represents an intensity-limiting time function, (ii) $\mathrm{k}_{\mathrm{dec}}$ represents an intensitydecreasing time constant (in $\mathrm{s}^{-1}$ ) and (iii) $\mathrm{N}_{0}$ is the odorant molecule amount in the nasal cavity that is constant with time since the $\mathrm{OH}$ experiments were performed under continuous delivery of odorant at constant concentration [6]. Let us further assume that $\mathrm{L}(\mathrm{t})$ can be expressed by means of a sum of exponentially time-decreasing functions $\left(\mathrm{L}_{\mathrm{i}}(\mathrm{t})\right.$; amplitude: $\mathrm{L}_{\mathrm{i}}$, in arbitrary unit; time constant: $\mathrm{k}_{\mathrm{Li}}$, in $\mathrm{s}^{-1}$ ):

$$
\mathrm{L}(\mathrm{t})=\sum \mathrm{L}_{\mathrm{i}}(\mathrm{t})=\sum \mathrm{L}_{\mathrm{i}} \times \exp \left(-\mathrm{k}_{\mathrm{Li}} \times \mathrm{t}\right)
$$

As a consequence, the solution of Equation (1) is a sum of separate processes, i.e., $\mathrm{S}_{\mathrm{i}}(\mathrm{t})$, each involving its own intensity-limiting parameters $\left(\mathrm{A}_{\mathrm{i}}, \mathrm{k}_{\mathrm{Li}}\right)$, but all having the same intensitydecreasing time constant $\left(\mathrm{k}_{\mathrm{dec}}\right)$ :

$$
\mathrm{S}(\mathrm{t})=\sum \mathrm{S}_{\mathrm{i}}(\mathrm{t})=\sum \mathrm{S}_{\mathrm{i}} \times\left[\exp \left(-\mathrm{k}_{\mathrm{Li}} \times \mathrm{t}\right)-\exp \left(-\mathrm{k}_{\mathrm{dec}} \times \mathrm{t}\right)\right] /\left[\mathrm{k}_{\mathrm{dec}}-\mathrm{k}_{\mathrm{Li}}\right]
$$

where $S_{i}=N_{0} \times L_{i}$ (in arbitrary unit: a.u.).

\subsection{Fitting of $\mathrm{OH}$ centroid curves}

We preliminarily verified the Equation-(1) assumption of the 1 intensity-decreasing time constant $\left(\mathrm{k}_{\mathrm{dec}}\right)$ by fitting the last part of the $\mathrm{HH}$ curve with a mono-exponentially decreasing function (GraphPad Prism software, version 5.00).

Then, since intensity ratings previously reported by Sinding et al. always started at level 6 (by using a device that transformed pressure into a signal ranging between 0 and 10), the fitting of each experimental $\mathrm{OH}$ curve was performed by using nonlinear regression (GraphPad Prism software, version 5.00) from this level and over the entire stimulation period 
of 120 s. Different fittings of Equation (3) on $\mathrm{HH}-\mathrm{MH}-\mathrm{LH}$ experimental data were performed assuming L(t) involves 1 or a sum of several intensity-limiting functions, in other words, assuming $\mathrm{S}(\mathrm{t})$ involves 1 or a sum of several processes.

\subsection{Statistical analysis}

The fittings allowed us to assess parameters involved in Equation (3), i.e., $\mathrm{S}_{\mathrm{i}}, \mathrm{k}_{\mathrm{Li}}$ and $\mathrm{k}_{\text {dec }}$ for each $\mathrm{HH}-\mathrm{MH}-\mathrm{LH}$ curve, respectively, along with their standard deviation (SD). In the framework of a two-process $\mathrm{OH}$ signal, i.e., involving the 5 parameters $\mathrm{S}_{1,2}, \mathrm{k}_{\mathrm{L} 1,2}$ and $\mathrm{k}_{\mathrm{dec}}$, standard deviation of the ratio $\mathrm{S}_{1} / \mathrm{S}_{2}$ was computed from the following equation for each $\mathrm{HH}-$ MH - LH curve:

$$
\left(\mathrm{SD}_{\mathrm{S} 1 / \mathrm{S} 2}\right)^{2}=\left(\mathrm{S}_{1} / \mathrm{S}_{2}\right)^{2}\left[\left(\mathrm{SD}_{\mathrm{S} 1} / \mathrm{S}_{1}\right)^{2}+\left(\mathrm{SD}_{\mathrm{S} 2} / \mathrm{S}_{2}\right)^{2}\right]
$$

A weighted mean value of $\mathrm{k}_{\mathrm{L} 1}$ was obtained from the 3 values and their SD assessed from the $3 \mathrm{HH}-\mathrm{MH}-\mathrm{LH}$ curves, as:

$$
<\mathrm{k}_{\mathrm{L} 1}>=\mathrm{SD}_{\mathrm{kL} 1}{ }^{2}\left[\mathrm{k}_{\mathrm{L} 1-\mathrm{HH}} /\left(\mathrm{SD}_{\mathrm{kL} 1-\mathrm{HH}}\right)^{2}+\mathrm{k}_{\mathrm{L} 1-\mathrm{MH}} /\left(\mathrm{SD}_{\mathrm{kL} 1-\mathrm{MH}}\right)^{2}+\mathrm{k}_{\mathrm{L} 1-\mathrm{LH}} /\left(\mathrm{SD}_{\mathrm{kL} 1-\mathrm{LH}}\right)^{2}\right]
$$

with $\mathrm{SD}_{\mathrm{kL} 1}^{2}$ computed from the equation:

$$
\mathrm{SD}_{\mathrm{kL} 1}{ }^{2}=\left[\left(1 / \mathrm{SD}_{\mathrm{kL} 1-\mathrm{HH}}\right)^{2}+\left(1 / \mathrm{SD}_{\mathrm{kL} 1-\mathrm{MH}}\right)^{2}+\left(1 / \mathrm{SD}_{\mathrm{kL} 1-\mathrm{LH}}\right)^{2}\right]^{-1}
$$

For all statistical tests, a P-value below 0.05 was considered to be statistically significant. Confidence intervals of the parameter estimates were calculated as $1.96 \times \mathrm{SD}$, with $95 \%$ reliability. 


\section{Results}

The preliminary fitting of the last part of the $\mathrm{HH}$ curve with a mono-exponentially decreasing function, yielded a correlation coefficient of $R=0.9989$ (range $50-120 \mathrm{~s}$; graph not shown), thus allowing us the fitting of Equation (3) on $\mathrm{HH}-\mathrm{MH}-\mathrm{LH}$ experimental data. The highest correlation coefficient of Equation-(3) fitting on $\mathrm{HH}-\mathrm{MH}-\mathrm{LH}$ experimental data was obtained when $\mathrm{S}(\mathrm{t})$ involves two processes: $R=0.9997-0.9995-0.9962$ for the graph displaying $\mathrm{HH}-\mathrm{MH}-\mathrm{LH}$ experimental versus theoretical data (Figure 1a,b,c; $\mathrm{n}=465$ - $466-465 ; P<0.001$ ), respectively (graphs of one-process $\mathrm{HH}-\mathrm{MH}-\mathrm{LH}$ not shown). We therefore did not further probe a three-process fitting, and $\mathrm{S}(\mathrm{t})$ can be expressed as:

$$
\begin{aligned}
\mathrm{S}(\mathrm{t})= & \mathrm{S}_{1}(\mathrm{t})+\mathrm{S}_{2}(\mathrm{t}) \\
& =\mathrm{S}_{1} \times\left[\exp \left(-\mathrm{k}_{\mathrm{L} 1} \times \mathrm{t}\right)-\exp \left(-\mathrm{k}_{\mathrm{dec}} \times \mathrm{t}\right)\right] /\left[\mathrm{k}_{\mathrm{dec}}-\mathrm{k}_{\mathrm{L} 1}\right] \\
& +\mathrm{S}_{2} \times\left[\exp \left(-\mathrm{k}_{\mathrm{L} 2} \times \mathrm{t}\right)-\exp \left(-\mathrm{k}_{\mathrm{dec}} \times \mathrm{t}\right)\right] /\left[\mathrm{k}_{\mathrm{dec}}-\mathrm{k}_{\mathrm{L} 2}\right]
\end{aligned}
$$

Figure 2 illustrates the respective part of intensity-limiting and intensity-decreasing mechanisms in the $\mathrm{HH}$ signal. Table 1 summarizes the fitting outcomes of the 5 parameters, i.e., $\mathrm{S}_{1,2}, \mathrm{k}_{\mathrm{L} 1,2}$ and $\mathrm{k}_{\mathrm{dec}}$, for $\mathrm{HH}-\mathrm{MH}-\mathrm{LH}$. Confidence intervals (CI; with $95 \%$ reliability) calculated from SD in Table 1 indicate that $\mathrm{S}_{2}$ and $\mathrm{k}_{\mathrm{L} 2}$ were significantly different between $\mathrm{HH}, \mathrm{MH}$ and $\mathrm{LH}$, respectively. Moreover, the ratio $\mathrm{S}_{1} / \mathrm{S}_{2}$ was significantly different between HH, MH and LH: $6.62 \pm 0.39,11.57 \pm 1.00$ and $18.07 \pm 2.48( \pm 95 \% \mathrm{CI})$, respectively. $\mathrm{A}$ weighted mean $\mathrm{k}_{\mathrm{L} 1}$ value was computed from $\mathrm{HH}-\mathrm{MH}-\mathrm{LH}$ data: $\left\langle\mathrm{k}_{\mathrm{L} 1}\right\rangle=0.35710 \pm$ $0.00451 \mathrm{~s}^{-1}$, that is, with $\pm 1.3 \%$ relative measurement uncertainty (95\% reliability). Figure 3a, b, c separately shows $S_{1}(t)$ and $S_{2}(t)$ expressed in the right hand side of Equation (7). In other words, the sum " $\mathrm{S}_{1}(\mathrm{t})+\mathrm{S}_{2}(\mathrm{t})$ " of the curves shown in Figure $3 \mathrm{a}, 3 \mathrm{~b}$ and $3 \mathrm{c}$ is the curve shown in Figure 1a, 1b and 1c for $\mathrm{HH}-\mathrm{MH}-\mathrm{LH}$, respectively. Figure 4 shows the comparison between $\mathrm{S}_{1}(\mathrm{t})$ of $\mathrm{HH}$ and $\mathrm{S}_{1}(\mathrm{t})$ of both $\mathrm{MH}$ and $\mathrm{LH}$, after arbitrarily setting the $\mathrm{k}_{\text {dec }}$ value of the latter to that of the former (Table 1). 


\section{Discussion}

Sinding et al. previously showed that the unconscious filter of $\mathrm{OH}$, which is designed to avoid brain overstimulation, depends on the odorant [6]. The authors illustrated this finding with 3 normalized centroid curves of different shapes, characterizing High Habituation, Medium Habituation and Low Habituation. These $\mathrm{OH}$ curves were obtained under constant olfactory stimulation, but all exhibited a similar pattern consisting in a peak followed by a decrease. Actually, this pattern can be interpreted as a combination of intensity-limiting and intensity-decreasing mechanisms, as illustrated in Figure 2 for HH. An intensity-limiting mechanism alone would lead the $\mathrm{OH}$ signal to reaching a plateau, even under conditions of a constant stimulation with an odorant, that differs from that of the maximum intensity perceived reported in literature [8]. The intensity-decreasing mechanism, which is effective simultaneously with the former, modifies this plateau by inducing a decrease. As a result, combining intensity-limiting and intensity-decreasing mechanisms generates a peak then followed by a decrease. Therefore, the current study aimed at deriving a general equation from a mathematical modelling analysis involving these 2 mechanisms (Equations (2-3-7)). Adjusting 4 intensity-limiting and 1 intensity-decreasing parameters of this general equation enabled us to fit each $\mathrm{HH}-\mathrm{MH}-\mathrm{LH}$ centroid curves, respectively. The finding of 1 intensity-decreasing time constant, i.e. $\mathrm{k}_{\mathrm{dec}}$, for each $\mathrm{HH}-\mathrm{MH}$ - LH curve, respectively, confirmed the preliminary fitting of the last part of the HH curve with a mono-exponentially decreasing function and, thereby, confirmed the Equation-(1) assumption of the 1 intensitydecreasing time constant. Correlation coefficients of experimental versus theoretical (Equation (7)) data fitting were high: $R=0.9997-0.9995-0.9962(P<0.001)$ for $\mathrm{HH}-\mathrm{MH}$

- LH (Figure 1), respectively. Moreover, for each quantitative parameter and for each $\mathrm{OH}$ degree, the SD was small in comparison with its estimate (Table 1). Hence, we believe that 
these features support the relevance of the proposed mathematical modelling analysis of the $\mathrm{OH}$ centroid curves in humans.

Equation (7) shows that the $\mathrm{OH}$ centroid curves result from the sum of 2 processes, i.e., " $\mathrm{S}_{1}(\mathrm{t})+\mathrm{S}_{2}(\mathrm{t})$ ", that are related to 2 intensity-limiting functions, i.e., $\mathrm{L}_{1}(\mathrm{t})$ and $\mathrm{L}_{2}(\mathrm{t})$ (Equation (2)), that exponentially decrease with a different time constant (Table 1). Comparison of $\mathrm{S}_{1}(\mathrm{t})$ and $\mathrm{S}_{2}(\mathrm{t})$ between $\mathrm{HH}, \mathrm{MH}$ and $\mathrm{LH}$ in Figure 3 apparently indicates that both are different in relation to the degree of $\mathrm{OH}$. However, after arbitrarily setting the $\mathrm{k}_{\mathrm{dec}}$ value in both MH and LH to that of $\mathrm{HH}$ (Table 1: $\left.\mathrm{k}_{\mathrm{dec}}=0.02286 \mathrm{~s}^{-1}\right)$, "corrected" $\mathrm{S}_{1}(\mathrm{t})$ of $\mathrm{MH}$ and LH then appears to be close to that of $\mathrm{HH}$, within 95\%-CI limit of $\mathrm{HH}$ in Figure 4. This finding is consistent with the comparison of $\mathrm{S}_{1}$ and $\mathrm{k}_{\mathrm{L} 1}$ values found for $\mathrm{HH}, \mathrm{MH}$ and $\mathrm{LH}$ in Table 1. Thus, the difference occurring in the decreasing part of $S_{1}(t)$ between $H H, M H$ and LH (Figure 3) is related to the value of the intensity-decreasing time constant that diminishes from $\mathrm{HH}$ to $\mathrm{LH}$ : the lower the $\mathrm{k}_{\mathrm{dec}}$ value, the shallower the decreasing part of $\mathrm{S}_{1}(\mathrm{t})$ and, in terms of $\mathrm{OH}$, the more prolonged the perception of odorant intensity. We therefore suggest that, whatever the $\mathrm{OH}$ degree, a first, shared, intensity-limiting mechanism occurs that is, nevertheless, tuned by the specific intensity-decreasing time constant of the $\mathrm{OH}$ degree. In contrast, $\mathrm{S}_{2}$ and $\mathrm{k}_{\mathrm{L} 2}$ values were significantly different between $\mathrm{HH}, \mathrm{MH}$ and $\mathrm{LH}$, respectively, ruling out such a sharing feature for $S_{2}(t)$ (Table 1). Furthermore, whereas $S_{2}(t)$ reinforces the $S_{1}(t)$ process in $\mathrm{HH}$ (Figure 3a), it plays a distinct role from $\mathrm{S}_{1}(\mathrm{t})$ in LH (Figure $3 \mathrm{c}$ ). Indeed, the lower the $\mathrm{OH}$ degree, the lower the $\mathrm{S}_{2}$ and $\mathrm{k}_{\mathrm{L} 2}$ value (Table 1) and the weaker the role of the second process, thus allowing prolonged perception of odor intensity, although at a low level. This prolonged perception in $\mathrm{LH}$ is strengthened by a low value of the intensity-decreasing time constant, in line with what has been above commented for $S_{1}(t)$.

An interpretation of the 2 processes involved in the $3 \mathrm{OH}$ centroid curves, i.e., $\mathrm{S}_{1}(\mathrm{t})$ and $S_{2}(t)$, may be hypothesized. Figure 3 shows that $S_{1}(t)$ plays a major role in the rising part 
and in the peak of each $\mathrm{OH}$ centroid-curve. We suggest that $\mathrm{S}_{1}(\mathrm{t})$ is very likely affected by the somewhat problematic onset ratings (even beginning at $\mathrm{y}=0.6$ ) and that, since the current modelling analysis established that $S_{1}$ and $k_{L 1}$ values were found to be shared by the whole $\mathrm{OH}$ centroid curves, these imperfect ratings affected in a similar manner both $\mathrm{HH}, \mathrm{MH}$ and LH centroid curves. As a consequence, we suggest that the first intensity-limiting mechanism, and, hence, $S_{1}(t)$, may be mainly related to the experimental design involving the whole unknown signal-transmission features occurring from the olfactory epithelium to the response given by the subject, who, furthermore, started intensity ratings at level 6 by using a device that transformed pressure into a signal ranging between 0 and 10. In other words, we suggest that $S_{1}(t)$ is unlikely related to the olfactory habituation itself and, rather, may possibly be of artifactual origin. In contrast, we hypothesize that $\mathrm{S}_{2}(\mathrm{t})$ plays a major role in the $\mathrm{OH}$ degree, since $S_{2}$ and $k_{L 2}$ values were found to be significantly different between $\mathrm{HH}, \mathrm{MH}$ and $\mathrm{LH}$, respectively. However, its origin is not clear and, at this stage of our work, $\mathrm{S}_{2}(\mathrm{t})$ cannot be specifically assigned to either peripheral or central adaptation, respectively. Due to the limited knowledge on the central processes involved in adaptation [7], we can assume that both central and peripheral adaptation very likely occur in combination for achieving $\mathrm{OH}$ during a 2-minute continuous odorant-stimulation condition. Finally, it should be noted that the mathematical expression of $S_{1}(t)$ and $S_{2}(t)$ is similar to that of the conductance change due to a presynaptic event [9], which thereby involves conductance-limiting and conductancedecreasing mechanisms.

The interpretation of the mathematical model analysis is limited regarding the amplitudes of $S_{1}(t)$ and $S_{2}(t)$, that is, about $S_{1}$ and $S_{2}$ in Equation (7). This is because the $\mathrm{HH}$ MH - LH curves were previously normalized before being fitted. Therefore, the amplitude comparison was limited to the $\mathrm{S}_{1} / \mathrm{S}_{2}$ ratio that was significantly different between $\mathrm{HH}, \mathrm{MH}$ and $\mathrm{LH}$, respectively (95\% reliability). This, nevertheless, remains of limited interest in 
contrast to comparing absolute values of the corresponding time constants $\mathrm{k}_{\mathrm{L} 1}$ and $\mathrm{k}_{\mathrm{L} 2}$ (Figure 3; Table 1). It is worth noting that $S_{1,2}$ were expressed as $S_{1,2}=L_{1,2} \times N_{0}$, and then if the $S_{1} / S_{2}$ ratio is known, the $\mathrm{L}_{1} / \mathrm{L}_{2}$ ratio is known too. Actually, $\mathrm{L}_{1,2}$ involves (i) the total number of different receptors recruited by an arbitrary odorant molecule that might depend on the process and on $\mathrm{N}_{0}$ [8], respectively, and (ii) the whole unknown signal-transmission features occurring from the olfactory epithelium to the intensity ratings that might depend on the process.

Since the current modelling analysis allowed us to distinguish between $S_{1}(t)$ and $S_{2}(t)$, and that $\mathrm{S}_{2}(\mathrm{t})$ may play a major role in the $\mathrm{OH}$ degree, we suggest that a future goal could be to implement the current modelling analysis in $\mathrm{OH}$ centroid curves obtained for different odorants, focusing on $\mathrm{S}_{2}(\mathrm{t})$, that is, on $\mathrm{S}_{2}, \mathrm{k}_{\mathrm{L} 2}$ and $\mathrm{k}_{\mathrm{dec}}$. In such a framework, curve fitting might be simplified in comparison with the current one by assessing 4 parameters (i.e., $\mathrm{S}_{1,2}$, $\mathrm{k}_{\mathrm{L} 2}$ and $\mathrm{k}_{\mathrm{dec}}$ ), instead of 5 parameters, since the current results allow us to assume that $\mathrm{k}_{\mathrm{L} 1}$ is identical for any odorant. Determinants of $\mathrm{OH}$ that have been previously reported could be reexamined, as well as combinations of factors [6]. Furthermore, a dose-dependency of the intensity-limiting and intensity-decreasing mechanisms, and, hence, of $S_{1}(t)$ and $S_{2}(t)$, could be investigated. Dose-dependent changes in the parameter values of the mechanisms may indeed be expected. The efficiency of the clustering analysis, and, hence, the accuracy of the proposed mathematical modelling analysis, will require a great amount of data for such investigations in order to get rid of random and unwanted factors, including technical and emotional factors [10].

To conclude, for the first time, to the best of our knowledge, a mathematical modelling analysis is proposed enabling us to fit different degrees of human $\mathrm{OH}$ corresponding to 3 centroid curves extracted from a clustering analysis [6]. By simply adjusting 5 parameters involved in the same general equation, fitting correlation coefficients of $\mathrm{HH}-\mathrm{MH}-\mathrm{LH}$ 
curves were high: $0.9997-0.9995-0.9962$, respectively. The general equation suggests that each $\mathrm{OH}$ centroid curve results from the simultaneous effect of 2 separate processes, i.e. $\mathrm{S}_{1}(\mathrm{t})$ and $\mathrm{S}_{2}(\mathrm{t})$, each involving its own intensity-limiting mechanism but having the same intensitydecreasing mechanism, respectively. The first process, i.e. $S_{1}(t)$, is of unclear, possibly artifactual origin, and, thereby, is unlikely related to the olfactory habituation itself. In contrast, we suggest that the second process, i.e. $\mathrm{S}_{2}(\mathrm{t})$, which appeared to depend on the odorant, plays a major role in the $\mathrm{OH}$ degree and cannot be assigned, a priori, to either peripheral or central adaptation, respectively. The proposed mathematical modelling analysis emphasizes that relevant olfactory research data can be obtained in a non-invasive manner, putting forward the usefulness of the clustering-analysis tool. 


\section{Author Contributions}

Mathematical modelling analysis: E.L.; interpretation of the mathematical modelling analysis: E.L., C.S; design of the study, discussion, writing and reviewing of the manuscript: E.L., T.H., R.M., C.S.

\section{Competing interests}

The authors declare no competing interests. 


\section{References}

1. R. F. Thompson, W.A. Spencer, Habituation: a model phenomenon for the study of neuronal substrates of behaviour, Psychol. Rev. 73 (1966) 16-43.

2. D.A. Wilson, Habituation of odor responses in the rat anterior piriform cortex, J. Neurophysiol. 79 (1998) 1425-1440.

3. A. Poellinger, Activation and habituation in olfaction — an fMRI study, Neuroimage. 13 (2001) 547-560.

4. R.F. Thompson, Habituation: a history. Neurobiol. Learn. Mem. 92 (2009) 127-134.

5. C.H. Rankin, Habituation revisited: an updated and revised description of the behavioral characteristics of habituation, Neurobiol. Learn. Mem. 92 (2009) 135-138.

6. C. Sinding, F. Valadier, V. Al-Hassani, G. Feron, A. Tromelin, I. Kontaris, T. Hummel, New determinants of olfactory habituation. Sci. Rep. 7 (2017) 41047-41058.

7. R. Pellegrino, C. Sinding, R.A. de Wijk, T. Hummel, Habituation and adaptation to odors in humans. Physiol Behav. 177 (2017) 13-19.

8. M. Chastrette, T. Thomas-Danguin, E. Rallet, Modelling the human olfactory stimulusresponse function. Chem Senses. 23 (1998) 181-196.

9. C. Linster, A.V. Menon, C.Y. Singh, D.A. Wilson, Odor-specific habituation arises from interaction of afferent synaptic adaptation and intrinsic synaptic potentiation in olfactory. Learn. Mem. 16 (2009) 452-459.

10. J. Lötsch, D. Kringel, T. Hummel, Machine learning in human olfactory research. Chemical Senses 44 (2019) 11-22. 
Table 1. Fitting results ( \pm SD) of intensity-versus-time OH curves, by using Equation (7).

\begin{tabular}{lccc}
\hline & High Habituation & Middle Habituation & Low Habituation \\
\hline $\mathrm{S}_{1}$ (a.u.) & $0.245 \pm 0.003$ & $0.266 \pm 0.002$ & $0.271 \pm 0.002$ \\
$\mathrm{k}_{\mathrm{L} 1}\left(\mathrm{~s}^{-1}\right)$ & $0.32463 \pm 0.00718$ & $0.36156 \pm 0.00447$ & $0.35525 \pm 0.00287$ \\
$\mathrm{~S}_{2}$ (a.u.) & $0.037 \pm 0.001$ & $0.023 \pm 0.001$ & $0.015 \pm 0.001$ \\
$\mathrm{k}_{\mathrm{L} 2}\left(\mathrm{~s}^{-1}\right)$ & $0.05416 \pm 0.00201$ & $0.03220 \pm 0.00099$ & $0.01042 \pm 0.00007$ \\
$\mathrm{k}_{\mathrm{dec}}\left(\mathrm{s}^{-1}\right)$ & $0.02286 \pm 0.00027$ & $0.01253 \pm 0.00020$ & $0.01042 \pm 0.00049$ \\
\hline
\end{tabular}


a)

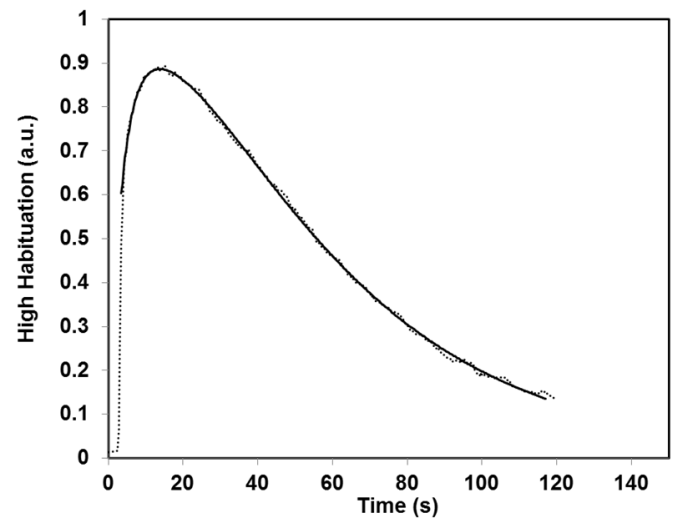

b)

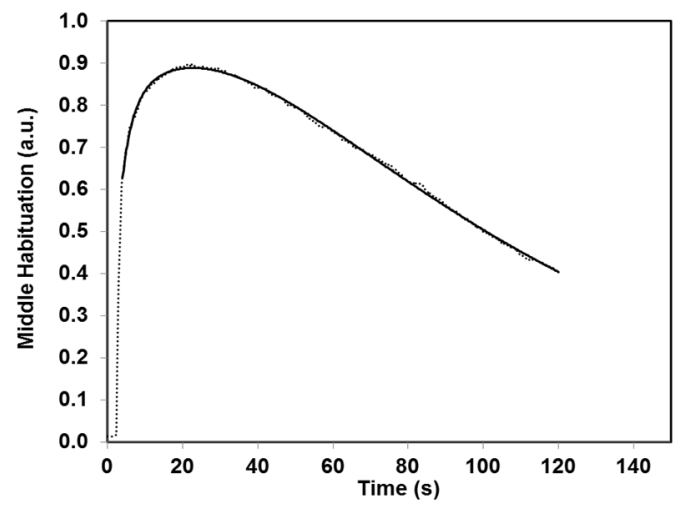

c)

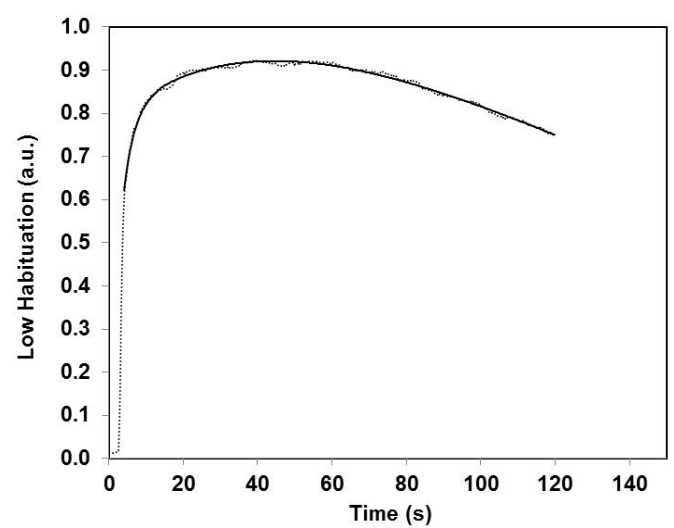

Figure 1. Fitting of intensity-versus-time $\mathbf{O H}$ centroid curves. Intensity in arbitrary unit (a.u.) and time in second (s). Experimental data (dotted line) and fitting outcomes of Equation (7) (full line) for a) HH $(R=0.9997)$, b) $\mathrm{MH}(R=0.9995)$ and c) LH $(R=0.9962)$, respectively $(P<0.001$ for all curves $)$. All fittings started at $\mathrm{y}=0.6$ since subjects were asked to start evaluating intensity at the level 6 (range 0 to10). 


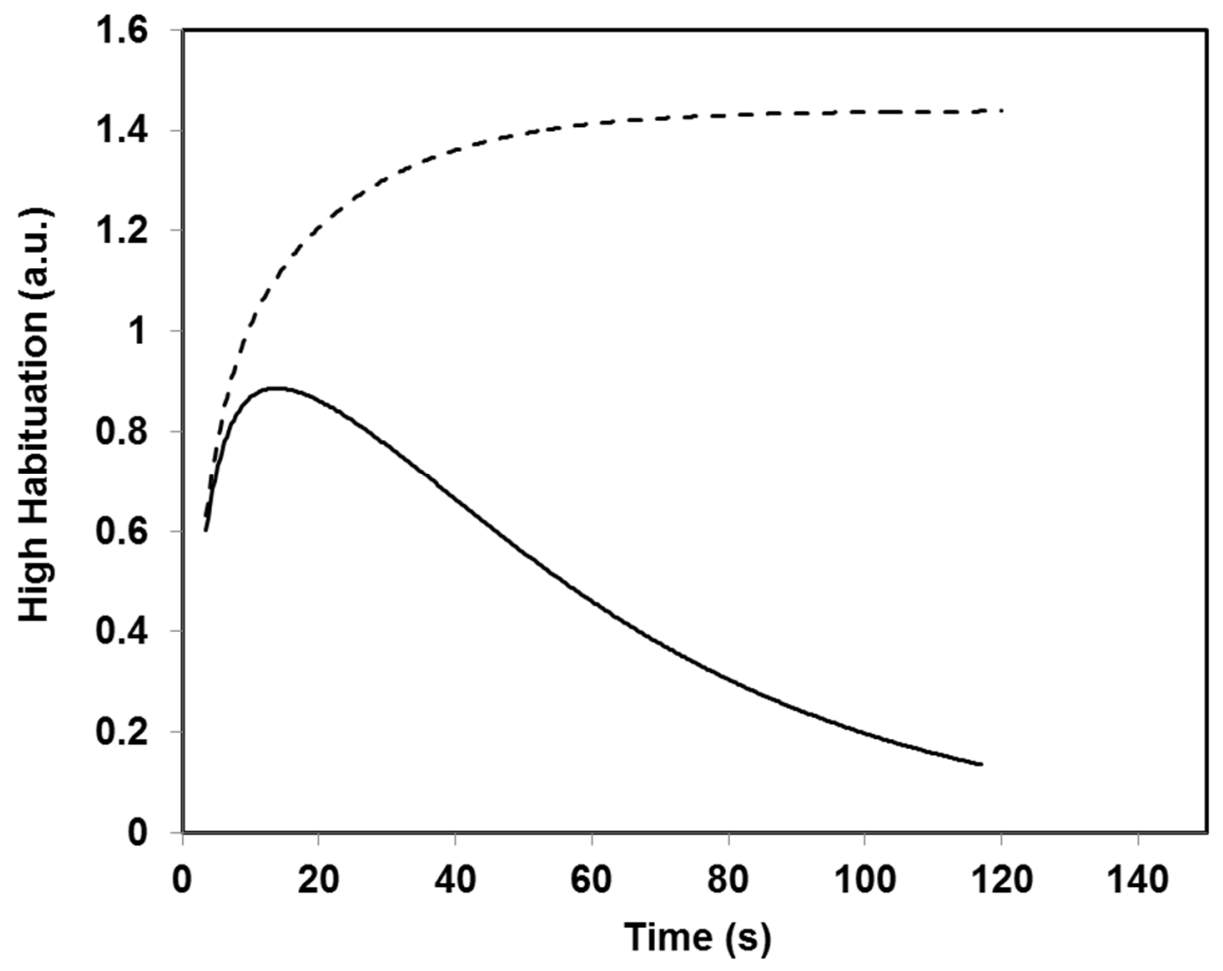

Figure 2. Intensity-limiting versus intensity-decreasing mechanisms for HH.

Fitting outcomes of Equation (7) already shown in Figure 1a (full line), versus outcomes of Equation (7) after setting $\mathrm{k}_{\mathrm{dec}}$ to zero (dashed line). 
a)

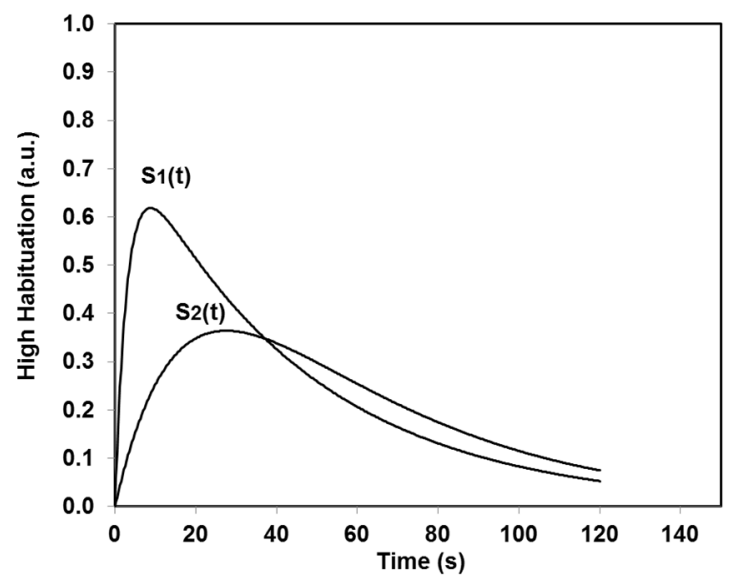

b)

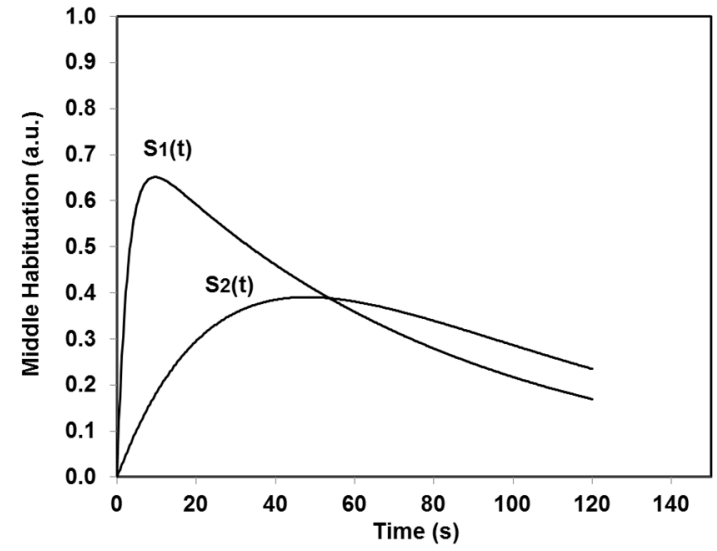

c)

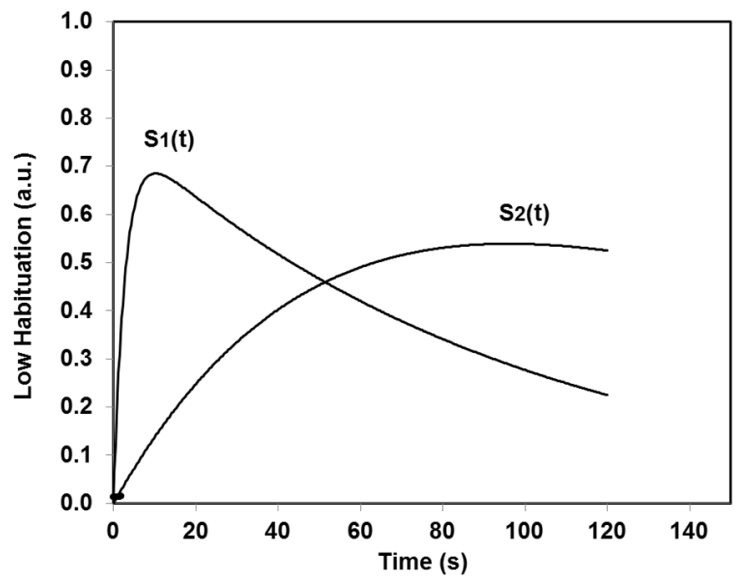

Figure 3. Role in the whole $O H$ centroid curves the 2 processes $S_{1}(t)$ and $S_{2}(t)$.

$\mathrm{S}_{1}(\mathrm{t})$ and $\mathrm{S}_{2}(\mathrm{t})$ involve the parameter estimates assessed by fitting the whole $\mathrm{OH}$ centroid curves (Table 1), for a) $\mathrm{HH}$, b) $\mathrm{MH}$ and c) $\mathrm{LH}$, respectively. The resulting curve of the sum " $\mathrm{S}_{1}(\mathrm{t})+\mathrm{S}_{2}(\mathrm{t})$ " in Figure 3a, b, c is the curve shown in Figure 1a, b, c, respectively. 




Figure 4. Comparison between $\mathrm{S}_{1}(\mathrm{t})$ of $\mathrm{HH}, \mathrm{MH}$ and $\mathrm{LH}$.

$\mathrm{S}_{1}(\mathrm{t})$ of $\mathrm{HH}, \mathrm{MH}$ and $\mathrm{LH}$ was compared after arbitrarily setting the same $\mathrm{k}_{\mathrm{dec}}$ value to both (full line); 95\% CI of the $\mathrm{HH} \mathrm{S}_{1}(\mathrm{t})$ curve is shown (dotted lines). 